\title{
TEORÍAS Y PRINCIPIOS NORMATIVOS EN BIOÉTICA
}

\author{
Rodolfo Vázquez \\ Instituto Tecnológico Autónomo de México (ITAM)
}

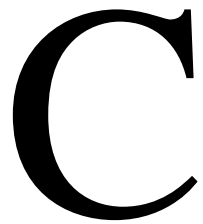

on este título me propongo considerar un tema que resulta de especial interés en bioética y que desde la publicación del libro de Tom Beauchamp y James Childress, Principles of Biomedical Ethics, en 1979, ${ }^{1}$ ha venido ocupando la atención de los filósofos dedicados al análisis de los problemas de medicina y salud, a saber, ¿las teorías éticas y los principios normativos deben considerarse relevantes para la resolución de los problemas prácticos, por ejemplo, en el seno de los diversos comités de ética hospitalarios? Si deben serlo, ¿qué tipo de teoría y qué características deben reunir tales principios para resultar pertinentes?

La pregunta no es trivial si pensamos por un momento que una de las demandas ciudadanas más frecuente a los comités nacionales de bioética o a los diferentes comités regionales o estatales, según las distintas especialidades, es la de orientar las decisiones a través de una normatividad que regule la conducta del personal sanitario y ayude al paciente actual o potencial en su requerimiento de asistencia sanitaria. La demanda es más urgente cuando se trata de problemas novedosos que, por lo general, al momento de su presentación, vienen acompañados de una serie de comentarios fatalistas con una fuerte carga emotiva que en poco contribuye a un juicio ponderado de la opinión pública.

Por lo general existen dos puntos de vistas encontrados en esta problemática. Por una parte, se piensa que ante la imposibilidad de alcanzar algún consenso entre las diferentes teorías morales, el filósofo «modesto» debe limitarse al oficio de técnico en su disciplina. Por la otra, el filósofo «ambi-

1 Tom Beauchamp y James Childress, Principles of Biomedical Ethics, Oxford University Press, 1979. El libro ha tenido sucesivas ediciones $(1983,1989,1994)$ en las cuales los autores han ido ajustando o corrigiendo su postura inicial. 
cioso» piensa que cualquier decisión pública se inscribe en un marco teórico que debe aplicarse a la resolución de cada uno de los casos que se presentan a consideración. ${ }^{2}$ Estos últimos, a su vez, abogan bien sea por una concepción generalista de la moral (ética deontológica, utilitarista, de derecho natural, por ejemplo) o una concepción particularista (contextualismo, casuística, ética del cuidado, de la virtud, entre otras posibles). En un terreno intermedio señalando las limitaciones de cada una de las dos posiciones extremas, se ubican aquellos filósofos que apelan a un «equilibrio reflexivo» entre principios generales y convicciones particulares, o bien reconocen la primacía de los principios pero no con un carácter absoluto, sino con un valor prima facie. Por cierto, estas dos últimas no son excluyentes. De acuerdo con este marco general he dividido el ensayo en cuatro partes: 1 . El filósofo modesto: el oficio de técnico; 2. El filósofo ambicioso generalista; 3. El filósofo ambicioso particularista; y 4. El filósofo de la tercera vía: principios prima facie y equilibrio reflexivo.

\section{El filósofo modesto: el oficio de técnico}

Después de caer en la cuenta de que es prácticamente imposible que los filósofos se pongan de acuerdo con respecto a alguna teoría moral, Mary Warnock se pregunta: «¿Cuál es, entonces, el lugar de la filosofía en las decisiones de los comités gubernamentales? Me parece que los filósofos juegan un papel simplemente como profesionistas, es decir, por entrenamiento y hábito están acostumbrados a distinguir las buenas de las malas evidencias, los argumentos correctos de las falacias, el dogma de la experiencia. Son profesionales acostumbrados a colocar las conclusiones y las líneas preliminares de un razonamiento de manera inteligible». ${ }^{3}$ En el mismo sentido se expresa Peter Singer: «la virtud distintiva de los filósofos es el pensamiento crítico - la habilidad para ponderar argumentos, detectar falacias y evitarlas en sus propio razonamiento». ${ }^{4}$

Más recientemente, el filósofo inglés radicado en México, Mark Platts, se plantea el mismo interrogante: «¿cómo podría el filósofo en tanto filósofo colaborar en la resolución de los problemas prácticos morales? ¿Qué contribución distinta nos permite un entrenamiento filosófico?». Desde un enfoque analítico, Platts divide la respuesta en dos partes: a) si es cierto que

${ }^{2}$ Cfr. Will Kymlicka, «Moral Philosophy and Public Policy: The Case of New Reproductive Technologies», en Wayne Sumner y Joseph Boyle (ed.), Philosophical Perspectives on Bioethics, University of Toronto Press, Canadá, 1996, pp. 244s.

${ }^{3}$ Mary Warnock, «Embryo Therapy: The Philosopher's Role in Ethical Debate», citado por Will Kymlicka, ibid., p. 250.

${ }^{4}$ Pascal Kasimba y Peter Singer, «Australian Comission and Committees on Issues in Bioethics», Journal of Medicine and Philosophy, Vol. 14, 1989, p. 406. 
el primer objetivo de la ética es un objetivo descriptivo, es decir, la identificación de la institución de la moralidad y la descripción de sus presupuestos conceptuales más generales, entonces, el análisis «de nuestro discurso moral cotidiano, llevado a cabo a la luz de las mejores teorías filosóficas de la conducta lingüística, es nuestra única guía segura al principio de la tarea descriptiva mencionada»; y b) si lo que se intenta es una claridad reflexiva sobre los conceptos, esto se hace con el propósito de llegar a una resolución razonable de los problemas en litigio, es decir, «la discusión sobre las pretendidas soluciones tiene que involucrar razonamientos, argumentos en favor o en contra de las supuestas soluciones. Tales argumentos pueden ser buenos, malos o dudosos; pero si no existe la pretensión de ofrecer buenos argumentos, la discusión no puede ser razonable».

Platts es consciente que con este doble objetivo la contribución del filósofo no adopta la forma de teoría o tesis sobre la moralidad, sino modestamente la de una debida utilización de las técnicas que son producto de su entrenamiento. Sin embargo, ¿no resulta esta contribución demasiado modesta, se cuestiona el mismo Platts, si con un poco que observemos el discurso moral cotidiano notamos que la gente común y corriente sostiene tesis sobre el carácter objetivo o subjetivo de las distintas moralidades? ¿No defienden los individuos acaso ideas metafísicas acerca de la libertad de la voluntad en contra del determinismo? ¿Y quién sino el filósofo puede ofrecer opiniones competentes sobre estas tesis? «Quizá, quizá, quizá..., pero lo dudo, piensa Platts, por lo menos en tanto que verdad generalizada sobre la institución humana de la moralidad». Lo que quiere decir este autor es que si bien no se puede negar la existencia de ideas cuasifilosóficas en el discurso moral de la gente y aún en los mismos códigos de ética médica, de aquí no se sigue que tales ideas sean elementos indispensables para las moralidades cotidianas y para tales códigos. Con su maestro Peter Strawson, Platts sostiene que: «La moralidad no requiere en la práctica ningún [...] anclaje metafísico, aun cuando algunos de quienes la practican estén dispuestos a imaginar, en sus momentos de reflexión, que sí lo necesita». ${ }^{5}$

No cabe duda que la contribución de la filosofía analítica en el nivel de la metaética ha sido relevante y fértil, pero también insuficiente. El problema, creo, es que los argumentos pueden ser claros e incluso consistentes, pero aún así pueden ser moralmente aberrantes o simplemente inicuos para ponderar alguna consideración moral. Las respuestas se desplazarían del campo de la moral al campo de la economía, de la estética o del auto-interés. Y esto no es poca cosa. Renunciar a la posibilidad de construir ciertos

${ }^{5}$ Cfr. Mark Platts, Sobre usos y abusos de la moral. Ética, sida y sociedad, PaidósUNAM, México, 1999, Apéndice: ética y práctica, pp. 139s. 
principios normativos generales que tomen como punto de partida el respeto hacia las personas es renunciar al «punto de vista moral», a la perspectiva desde la cual el individuo intenta ponerse en el lugar del otro. Si alguna cosa parece clara como punto de acuerdo entre las diversas teorías morales es la vieja Regla de Oro: actúa hacia los demás de la misma manera que quisieras que actuaran contigo. Esta regla se encuentra presente no sólo en la ética judeo-cristiana, sino bajo enunciados diversos, también en la ética deontológica de Kant, en utilitaristas como Bentham y Mill, contractualistas como Scanlon y en éticas del «cuidado» como la de Gilligan. ${ }^{6}$ Asumir el punto de vista moral es asumir, a fin de cuentas, el punto de vista de la imparcialidad, es decir, la posibilidad de valorar los conflictos en términos de principios generales que se acepten independientemente de la situación en particular, sin permitir que mis preferencias o prejuicios personales influyan en el juicio. Es reconocer, como insistentemente lo ha señalado Richard Hare, que el pensamiento moral se mueve en dos niveles: el intuitivo y el crítico. Muchos de los problemas morales surgen porque en el nivel intuitivo, tales intuiciones -intra o interpersonales- entran en conflicto, y ellas mismas están lejos de autojustificarse. Se requiere de un nivel diferente para dar respuesta a esos conflictos; un nivel crítico que sea empleado «no sólo para resolver conflictos entre intuiciones en el nivel intuitivo, sino para seleccionar los principios morales y [...] las virtudes que debemos cultivar en nuestros hijos y en nosotros mismos.» En otros términos: «Los principios parciales en el nivel intuitivo deben justificarse por un razonamiento imparcial en el nivel crítico.» ${ }^{7}$

Es claro, como sostienen Strawson y Platts, que en la práctica -en el nivel intuitivo de Hare- la moralidad no requiere de un anclaje metafísico, pero difícilmente se puede negar la necesidad de principios en el nivel crítico, si no es a condición de renunciar a la misma moralidad. Y creo que de esto toma conciencia Platts cuando al final de su libro se pregunta aguda y puntualmente: «¿No hay acaso una tarea filosófica de evidente utilidad para tales debates [morales] cuyo objeto sea formular los principios morales generales que subyacen en los juicios morales más específicos que los individuos hacen en cada situación particular? ¿No podría ser un ejemplo de esta tarea la identificación, digamos, de algún principio de respeto a la autonomía que se encuentre detrás de los juicios más específicos sobre los asuntos de la confidencialidad y el consentimiento informado en la práctica médica?».

\footnotetext{
${ }^{6}$ Cfr. Will Kymlicka, op. cit., p. 251.

${ }^{7}$ Cfr. Richard Hare, «Methods of Bioethics: Some defective Proposals», en Wayne Sumner y Joseph Boyle (ed.), op. cit., pp. 29s.
} 
La respuesta de Platts es positiva y las cautelas que introduce para entender adecuadamente su posición me parecen sugerentes. En primer lugar, la identificación del principio de respeto a la autonomía debe entenderse como «la propuesta normativa de un principio que funcione para maximizar cierto tipo de coherencia "profunda" entre los juicios morales específicos ofrecidos»; y en segundo lugar, «que para que la identificación de tal principio del respeto a la autonomía en el contexto de los debates contemporáneos sobre problemas morales prácticos sea útil, se requiere que, tanto en términos de su contenido como en términos de sus relaciones lógicas con los juicios morales comunes y corrientes, el principio no se quede demasiado "distante" de aquellos juicios». ${ }^{8}$ Habría que preguntarle a Platts qué quiere denotar con la expresión «coherencia profunda» y con la metáfora espacial de la distancia. A mi juicio, no es sino una alusión hacia la necesidad de una ética crítica, en los términos de Hare. Lo sugerente de su propuesta es que el acceso a los principios -al principio de autonomía, en este caso- está lejos de darse por la vía de intuiciones metafísicas de las cuales se pueda deductivamente inferir la solución para los conflictos morales específicos. La vía más bien es la inversa. Una suerte de inducción que concluya en la construcción de los principios normativos generales. Quisiera ahora detenerme a analizar la propuesta de lo que con Kymlicka he llamado, filósofos ambiciosos.

\section{El filósofo ambicioso generalista}

A diferencia de la modestia que caracteriza a aquellos que limitan la función del filósofo moral a sus habilidades técnicas, propias de su profesión, los filósofos ambiciosos piensan que las comisiones gubernamentales deberían adoptar una teoría moral comprensiva y aplicarla a las diversas situaciones o casos médicos, o de salud en general. Esta pretensión es fuertemente criticada por Kymlicka cuando se pregunta sobre las teorías morales, sean generalistas o particularistas: ¿qué es lo distintivo de cada una de ellas? ¿cuál es la más adecuada? ¿qué conclusiones prácticas se siguen de cada una para la resolución de problemas? ${ }^{9}$

Con respecto a la primera pregunta, piensa Kymlicka, parece que no existe algún criterio relevante que distinga a una teoría de otra. Por ejemplo, qué distingue a una ética contractual de una deontológica o utilitarista. Si tomamos el caso de John Rawls, algunas lecturas de su obra enfatizan su deuda deontológica con Kant, otras insisten en que el método constructivista conduce de hecho al utilitarismo y no ha faltado quien argumentara a

\footnotetext{
${ }^{8}$ Mark Platts, op. cit., pp. 155-156.

9 Will Kymlicka, op. cit., pp. 246s.
} 
favor de una ética del cuidado implícita en la explicación de la posición original. Rawls mismo en A Theory of Justice se considera contractualista y deontologista. Otros autores han subsumido el contractualismo bajo el utilitarismo y las teorías de derecho natural bajo las deontológicas, y así, terminan reduciendo las teorías éticas a la oposición más radical entre consecuencialistas y deontologistas. Otros, rechazan ambas por su carácter abstracto, a-histórico e impersonal, y reducen las teorías a éticas contextualistas. Resulta entonces imposible ponerse de acuerdo sobre la identidad y clasificación de las teorías éticas. Creo que Kymlicka no está diciendo que los debates en torno a la identidad de las teorías o la exégesis de las obras de los grandes teóricos morales sea irrelevante para la discusión filosófica. Lo que dice, y pienso que resulta una obviedad, es que para aquellos que deben tomar decisiones públicas o recomendarlas, el mapa de las teorías se presenta confuso, y el tiempo que disponen para decidir es limitado.

Pero supongamos que se logre identificar las teorías y clasificarlas con claridad, todavía hay que preguntarse cómo poner de acuerdo a los integrantes de los comités para evaluarlas y finalmente escoger la más adecuada. Si bien creo que es posible proponer con cierta objetividad algunos principios morales y también creo en la posibilidad de dar respuestas correctas -no absolutas- a los problemas morales, como veré más adelante, sería ingenuo suponer que existe un argumento unificador de todas las teorías y un principio absoluto regulador de todos los comportamientos humanos.

Sin embargo, aún si asumimos que todos hemos llegado a un acuerdo con respecto a una sola de las teorías éticas, se tiene que decidir todavía cómo aplicarla a las situaciones particulares. Y esta no es una tarea sencilla si pensamos que no existe un consenso generalizado de cómo deban entenderse cada una de las expresiones básicas que caracterizan a las diferentes teorías: «acuerdo», «utilidad», «naturaleza», «cuidado», «deber», pero, sobre todo, cómo deban usarse para dar respuesta a los distintos problemas que plantea la medicina y la salud. Todo parece indicar que es poco realista pensar que en los comités se puede llegar a un consenso en la selección y aplicación de alguna teoría moral. Pero además, pienso que esta pretensión de uniformidad resultaría inapropiada si se quiere corresponder a las demandas plurales de los ciudadanos en una sociedad democrática.

El carácter ambicioso del filósofo consiste, precisamente, en pensar que es posible identificar y clasificar las teorías; que puede seleccionarse una, que bajo un principio regulador, deba aplicarse incondicionalmente; y que esta teoría es la apropiada para responder a las demandas de todos los ciudadanos. No necesito agregar que una pretensión de este tipo puede llegar a tener una fuerte dosis de autoritarismo moral y que, desgraciadamente, no son pocos los comités de bioética, aún los no confesionales, que se distin- 
guen por ello. Entre los filósofos ambiciosos, el que aquí he denominado generalista, se caracteriza por una posición metaética absolutista y por lo que Dan Brock ha llamado el método deductivista de razonamiento moral. ${ }^{10}$

Tom Beauchamp ofrece una buena caracterización de los principios a partir de lo que él llama una «concepción robusta» y que contrapone a la concepción «prima facie», que él sostiene, y que analizaré más adelante. Esta concepción robusta, propia de lo que aquí he calificado de posición absolutista, sostiene que $x$ es un principio moral si y sólo si $x$ es: general, normativo, sustantivo, no exceptuable y fundacional. ${ }^{11}$ Es general porque un principio es aplicable para normar un amplio campo de circunstancias, y en este sentido contrasta con las proposiciones específicas; es normativo porque un principio es un standard de acciones correctas, buenas u obligatorias y posee la capacidad de dirigir acciones y ofrecer las bases para una evaluación crítica de las mismas; es sustantivo porque los principios expresan contenidos morales y no sólo la forma en que tales contenidos deben ser considerados; además, un principio moral no tiene excepciones aun si entra en conflicto con otros principios; y un principio fundamenta las reglas y los juicios morales sin justificarse a sí mismo en otro principio, ni esperar una justificación de tipo pragmática. Lo cuestionable de esta postura es el carácter no exceptuable y fundacional de los principios. Para el absolutismo moral los principios morales son inviolables, es decir, racionalmente incuestionables. Esto significa, como afirma Beauchamp, que no está moralmente justificado invalidarlos aun cuando exista un conflicto entre ellos. Estas situaciones, como es obvio, se presentan en un contexto trágico, donde nada de lo que uno hiciera sería moralmente aceptable o correcto. La alternativa sería o bien la no actividad, que incurriría en un acto de omisión moralmente reprobable, o bien la actividad, que entonces respondería no ya a razones objetivas sino a razones subjetivas que privilegiarían, dogmáticamente, un principio sobre los demás. Para el filósofo generalista todos los intentos de ofrecer razones en apoyo de las creencias últimas son superfluos. Las verdades morales, o bien se adquieren por una intuición metafísica no corroborable intersubjetivamente, o bien, en el extremo, por un acto de fe religiosa.

Con respecto al deductivismo, en los términos de Brock, consiste en emplear la verdadera teoría y principios, junto con los hechos empíricos relevantes a su aplicación, para deducir lógicamente la conclusión moral correcta para el caso o la política en cuestión. El problema es que no existe tal

${ }^{10} C f r$. Dan Brock, «Public Moral Discourse», en Wayne Sumner y Joseph Boyle (ed.), op. cit., pp. 279s.

${ }_{11}$ Tom Beauchamp, «Role of Principles in Practical Ethics», en Wayne Sumner y Joseph Boyle (ed.), op. cit., pp. 81s. 
teoría moral comprensiva en la que todos estén de acuerdo y que pueda ser aplicada deductivamente a las diversas situaciones. El deductivismo sería finalmente el método de razonamiento moral propio de las teorías fundacionalistas. Otro nombre para el absolutismo moral que, reitero, caracteriza a los filósofos generalistas.

Pienso que contra el absolutismo moral es necesario sostener la posibilidad de un control racional de nuestras creencias y, por lo tanto, invalidar cualquier argumento de autoridad aceptado dogmáticamente. A este respecto, nadie mejor que Popper ha visto con claridad la necesidad de anteponer a todo autoritarismo dogmático un racionalismo crítico fundado en la objetividad de la experiencia y en la disposición al diálogo crítico, lo que implica la confrontación de argumentos y la disponibilidad a abandonar las creencias cuando existen razones fundadas para hacerlo: «el autoritarismo y el racionalismo, tal como nosotros los entendemos, sostiene Popper, no pueden conciliarse puesto que la argumentación -incluida la crítica y el arte de escuchar la crítica- es la base de la racionalidad... La idea de imparcialidad también conduce a la de responsabilidad; no sólo tenemos que escuchar los argumentos sino que tenemos la obligación de responder allí donde nuestras acciones afecten a otros. De este modo, en última instancia, el racionalismo se halla vinculado con el reconocimiento de la necesidad de instituciones sociales destinadas a proteger la libertad de crítica, la libertad de pensamiento $\mathrm{y}$, de esta manera, la libertad de los hombres». ${ }^{12}$

\section{El filósofo ambicioso particularista}

Entre los filósofos ambiciosos, el que aquí he denominado particularista, se cracteriza por una concepción metaética subjetivista y por lo que a partir de la obra de Albert Jonsen y Stephen Toulmin ${ }^{13}$ se conoce como nueva casuística que, a diferencia de la «tiranía de los principios», centra su atención en el caso concreto. Entre los teóricos particularistas es recurrente incluir también a las defensores de las llamadas éticas de situación y las más recientes éticas de la virtud y del cuidado. No me detendré en estas últimas. ${ }^{14}$ Prefiero concentrar mi atención en dos posiciones que se ubican ple-

${ }^{12}$ Karl Popper, La sociedad abierta y sus enemigos, Paidós, Buenos Aires, 1967, Tomo II, pp. 317 y 336. Para Popper, la libertad de pensamiento y discusión racional son valores liberales que no requieren de ulterior justificación pero, y esto me parece relevante para no incurrir en la misma crítica que se hace del absolutismo moral, «pueden justificarse pragmáticamente sobre la base del papel que desempeñan en la búsqueda de la verdad». Ésta exige, al menos, «a) imaginación, b)ensayo y error, c) el descubrimiento gradual de nuestros prejuicios mediante a) y b) y la discusión crítica». En busca de un mundo mejor, Paidós, Barcelona, 1994.

${ }_{13}$ Albert Jonsen y Stephen Toulmin, The Abuse of Casuistry. A History of Moral Reasoning, University of California Press, 1988.

${ }_{14}$ Para un análisis crítico de estas teorías véase Richard Hare, op. cit. p. 19 y ss. 
namente en el debate de la bioética: el contextualismo de Earl Winkler y la ya mencionada casuística de Jonsen y Toulmin.

Winkler propone su concepción contextualista ${ }^{15}$ confrontándola críticamente con la teoría paradigmática de los principios tal como fue desarrollada por Beauchamp y Childress en su ya citado libro Principles of Biomedical Ethics. En la interpretación de Winkler la crítica a estos autores se centra en la idea de que la justificación moral que ofrece tal paradigma es esencialmente deductivista implicando diversos niveles de generalización: un juicio particular se justifica si cae bajo una regla y ésta lo hace mostrando que es una especificación de un principio general. De esta manera la bioética médica, por ejemplo, debe concebirse como una división primaria de la ética aplicada y, en definitiva, de una teoría ética general. Con poco que se analicen los tres principios fundamentales de la teoría paradigmática, continúa el autor, se cae en la cuenta de la deuda de cada uno de ellos con diversas teorías generalistas: el principio de autonomía es deudor de la ética kantiana, el de beneficencia (incluyendo aquí el de no-maleficencia) de la ética utilitarista y el de justicia del contractualismo. Cada una de estas teorías, coincidiría Winkler con Kymlicka, se enfrentaría con las interrogantes señaladas por este último y analizadas más arriba.

Para Winkler la teoría paradigmática no ofrece un criterio que permita decidir cuál de los principios debe seleccionarse en ciertas circunstancias concretas o, en otros términos, qué concepción teórica debe prevalecer. Precisamente, cuando se enfrenta a los casos límite, que son los más interesantes y conflictivos desde el punto de vista moral (el uso de niños anancefálicos como posibles donadores de órganos; la investigación con embriones y su uso en las nuevas técnicas reproductivas; por ejemplo), la teoría principalista incurre en omisiones serias. Parecería finalmente apelar a una suerte de intuicionismo difícilmente justificable desde un punto de vista empírico-racional. Por el contrario, el contextualismo en tanto procede metodológicamente «de abajo hacia arriba» considera que los problemas morales deben resolverse precisamente a la luz de la propia complejidad de las circunstancias concretas apelando a las tradiciones históricas y culturales relevantes. De esta manera, una teoría contextualista debe comenzar por el reconocimiento de una moral convencional con sus propias reglas y valores justificatorios, los mismos que deben considerarse con un criterio de validez instrumental de acuerdo con el contexto social que contiene el caso. Winkler concluye mostrando cómo cada uno de los principios -autonomía,

${ }^{15}$ Véase Earl Winkler. «Moral Philosophy and Bioethics: Contextualism versus the Paradigm Theory», en Wayne Sumner y Joseph Boyle (ed). op. cit., pp. 50 y ss. 
beneficencia y justicia- terminan relativizándose y apelando a principios supletorios para intentar dar una respuesta razonable a los casos concretos.

Para Jonsen y Toulmin debe recuperarse la casuística en el campo de la bioética, es decir, una forma de razonamiento que debe centrar su atención en el caso concreto. Lejos de partir de principios generales aplicables deductivamente de lo que se trata es de considerar las máximas y tópicos que definen el sentido y la relevancia del propio caso. Éstos, finalmente, deberán clasificarse en forma analógica de acuerdo con sus semejanzas y diferencias. En un escrito más reciente Albert Jonsen ha suavizado su casuística inicial destacando el papel que juegan las circunstancias en el juicio y en la responsabilidad moral de los agentes. ${ }^{16}$ En la Ética Nicomaquea de Aristóteles, en el De Officis de Cicerón y en La metafísica de las costumbres de Kant, obras fundacionales para diversas teorías éticas, se encuentran pasajes alusivos al papel relevante de las circunstancias: quién es el agente, qué hace, qué cosa o persona es afectada, qué medios usa, qué resultados se desean obtener con la acción, etc. La pregunta por las circunstancias, piensa Jonsen, no es una pregunta que demanda una respuesta por un sí o un no de acuerdo con principios rígidos, sino más bien, por una suerte de juicio prudencial. Las más de las veces, los casos difíciles conducen a situaciones donde las dos respuestas se presentan no como una situación dilemática, paralizante de la actividad, sino como conclusiones posibles de un razonamiento apoyado con buenos argumentos justificadores. En este contexto, las circunstancias adquieren un valor relevante en tanto «características moralmente apreciadas de una situación» y también decisorias para la situación particular. El caso concreto, entonces, debe verse como un todo en el que deben ponderarse los «menores riesgos», «los costos significativos», «los daños mínimos», etc. Ante la incapacidad de las máximas o tópicos para dirimir las situaciones conflictivas de lo que se trataría es de que el balance y la ponderación entre ellos dependiera de un juicio práctico moral, de la discreción, de la prudencia, o de lo que Aristóteles denominó phronesis. La casuística se resuelve finalmente en una suerte de apelación y ponderación de las circunstancias.

Ambas posturas -contextualista y casuística- incluidas dentro de la denominación general de particularistas, son criticables. Si en los generalistas el defecto era haber incurrido en un absolutismo moral bajo un esquema deductivista, el problema entre los particularistas es elaborar una teoría que descansa en un subjetivismo relativista y un método generalizador que no acierta a resolver tampoco, bajo criterios racionales, los conflictos frecuentes en bioética entre las propias máximas y tópicos.

\footnotetext{
${ }^{16}$ Albert Jonsen, «Morally Appreciated Circumstances: A Theoretical Problem for Casuistry», en Wayne Sumner y Joseph Boyle (ed.), op, cit, pp. 37 y ss.
} 
Earl Winkler critica con lucidez las posiciones generalistas aunque quizás exageró al extremo la teoría paradigmática de Beauchamp y Childress y no reconoció -como en seguida veremos- el valor prima facie de los principios defendidos por estos autores. Sea de ello lo que fuere, el problema de su contextualismo es el mismo problema al que se enfrenta cualquier convencionalismo o relativismo cultural. Si por éste se entiende la descripción del hecho sociológico de que las sociedades difieren en sus juicios éticos o de que los individuos tienden a tomar en cuenta las evaluaciones prevalecientes en su comunidad histórica y culturalmente determinada, esta afirmación es a todas luces verdadera pero irrelevante, ya que no afecta la validez ni la posibilidad de juicios moralmente universales. Si lo que se pretende es esto último, el relativismo es autodestructivo, porque su referente normativo no está contenido en las prácticas o convenciones de la sociedad. Como afirma Carlos Nino: «La dependencia de la crítica respecto de la práctica moral puede dar lugar a un relativismo conservador que, por un lado, es inepto para resolver conflictos entre quienes apelan a tradiciones o prácticas en el contexto de una sociedad, ya que la valoración presupondría esas prácticas y no es posible discriminar entre prácticas valiosas o disvaliosas sin contar con principios morales que sean independientes de ellas». ${ }^{17}$

La casuística de Jonsen y Toulmin se enfrenta a la crítica de Hare analizada más arriba: la insuficiencia de una moral intuicionista y la necesidad de asumir una ética crítica, imparcial, para resolver los conflictos entre las propias intuiciones, máximas o tópicos. Manuel Atienza lo ha expresado con claridad aludiendo a la obra de ambos autores: «el recurso que ellos sugieren a las máximas o tópicos es manifiestamente insuficiente para elaborar criterios objetivos de resolución de conflictos. Esto es así porque frente a un caso difícil (bien se trate del derecho, de la medicina o de la ética) existe siempre más de una máxima aplicable, pero de signo contradictorio; y el problema es que la tópica -o la nueva casuística de Jonsen y Toulmin- no está en condiciones de ofrecer una ordenación de esas máximas; o, mejor dicho, no podría hacerlo sin negarse a sí misma, pues eso significaría que, en último término, lo determinante serían los principios y las reglas -si se quiere, de segundo nivel- que jerarquizan las máximas». ${ }^{18}$ Por lo que hace a la apelación de Jonsen a la phronesis aristotélica cabe para ésta la misma crítica de Hare a las éticas intuicionistas. Como dice Atienza con razón: «estos autores parecen depositar una excesiva confianza en la prudencia o sa-

${ }_{17}$ Carlos Nino, «Liberalismo vs comunitarismo», Revista del Centro de Estudios Constitucionales, No. 1, Madrid, septiembre-diciembre, 1988, p. 367.

${ }^{18}$ Manuel Atienza, «Juridificar la bioética», en Rodolfo Vázquez (Comp.), Bioética y derecho, Fondo de Cultura Económica-ITAM, México, 1999, p. 69. 
biduría práctica... y en su capacidad para resolver en forma cierta (o, al menos, con toda la certeza que puede existir en las cuestiones prácticas) problemas específicos.» ${ }^{19}$

Para concluir este inciso quiero agregar algo que los críticos de una ética, con pretensiones de universalidad, tienden a omitir o simplemente, no reconocer, y es el hecho de que asumir un punto de vista imparcial no es ignorar que el discurso moral -y para nuestro caso el de la bioética- también se mueve en un mundo real. Nada más concreto, por ejemplo, que tomar como punto de partida las circunstancias de la justicia, las convicciones espontáneas para un equilibrio reflexivo o el reconocimiento de las necesidades básicas, como es de sobra conocido en autores como Herbert Hart, John Rawls o Ernesto Garzón Valdés, respectivamente; pero, precisamente, son un punto de partida que apunta hacia una empresa común más ambiciosa, como la posibilidad de lograr algún acuerdo entre puntos de vista distintos y encontrados. Para ello es necesario proporcionar razones objetivas para la acción y proponer un punto de vista imparcial que involucre a todos los seres humanos como agentes morales.

\section{El filósofo de la tercera vía: principios prima facie y equilibrio reflexivo}

Con la expresión «filósofo de la tercera vía» no quiero insinuar ningún compromiso de la bioética con propuestas políticas de moda, ni tampoco intentar jugar al papel de mediador. Por lo general estos últimos no dejan satisfecho a nadie y tienden a ser confusos en sus conclusiones. La idea de una tercera vía me fue sugerida en un texto de Norman Daniels ${ }^{20}$ en el que este autor manifestaba su asombro ante la riqueza de la disputa en el terreno de la bioética en torno a las teorías morales, los principios, las reglas y los juicios y acciones particulares. Después de haber trabajado durante los setenta en los problemas de una teoría general de la justicia y en el desarrollo de una concepción amplia del equilibrio reflexivo a partir de una revisión de las ideas de John Rawls, Daniels concluye que, con relación a los problemas de medicina y salud, no es apropiado aplicar sin más la teoría general y resolver los casos como si se tratara de un ejercicio deductivo. Los principios de justicia en Rawls fueron construídos a partir de un supuesto idealizado: personas capaces que especificarían los principios de justicia en el marco de una cooperación imparcial. Nadie se encontraba en situación de desventaja por razones de enfermedad o incapacidades físicas. Pero, enton-

\footnotetext{
19 Ibid.

${ }^{20}$ Norman Daniels, «Wide Reflective Equilibrium in Practice», en Wayne Sumner y Joseph Boyle (ed), op. cit., pp. 96 y ss.
} 
ces, ¿debía añadir la teoría de Rawls otro bien primario: la salud? ¿Qué debía entenderse por «aplicar» los principios de una teoría general? ${ }^{21}$ Daniels se figura el debate como si se encontrara en un campo de batalla y en el que como corresponsal realiza «Un breve reporte desde la zona de guerra en la tierra de Bioética» (The Land of Bioethics). El campo de batalla está seccionado en diferentes niveles donde se ubican en las zonas altas los «Uplanders», bandas protegidas en torno a las teorías generales; abajo en el valle se encuentran los «Lowlanders», contextualistas y casuísticos, que desconfían de los lugares altos y se deleitan sintiendo el polvo y el pasto bajo sus pies; y en un lugar intermedio, en una serie de colinas fortificadas con principios y reglas se encuentra los habitantes de «Middle Kingdom». Es a los habitantes de este reino intermedio a los que, afortunadamente o no, he llamado «filósofos de la tercera vía». Una zona de principios y reglas ubicada entre las teorías generales y las teorías particularistas. Después de este paréntesis veamos qué proponen estos autores.

He dicho más arriba que la alternativa del equilibrio reflexivo es compatible con la propuesta de considerar a los principios prima facie y no absolutos. Los defensores de ambas posturas no siempre hacen evidente este acuerdo y la razón puede deberse a la simple obviedad de que cualquier defensa del absolutismo moral excluiría la necesidad de ponderar los principios en ese juego de ida y regreso con las convicciones particulares, tal como lo propone John Rawls. Asumiré esta obviedad y no me detendré demasiado a buscar los vínculos entre una y otra respuesta. Comenzaré por exponer, brevemente, la teoría principalista de Tom Beauchamp y James Childress, y uno de los últimos escritos del primero ${ }^{22}$ donde modera la propuesta original atendiendo a algunas de las críticas más puntuales de su teoría. En seguida, analizaré la contribución de Dan Brock ${ }^{23}$ en el marco de la teoría del equilibrio reflexivo, y concluiré con la exposición y comentarios a un trabajo de Manuel Atienza. ${ }^{24}$ Con algunas divergencias menores y algún añadido adelanto mi acuerdo con la propuesta de Atienza desde la cual creo que puede ofrecerse alguna respuesta a las preguntas formuladas al inicio de este ensayo.

Como es bien conocida, la teoría de Beuachamp y Childress, se estructura a partir de un orden jerárquico de justificación desde las teorías éticas generales hasta los juicios particulares pasando por los principios y las re-

${ }^{21}$ Ibid., pp. 107-108.

${ }^{22}$ Tom Beauchamp, «The Role of Principles in Practical Ethics», en Wayne Sumner y Joseph Boyle (ed), op. cit., pp. 79 y ss.

${ }^{23}$ Dan Brock, op. cit.

${ }^{24}$ Manuel Atienza, op. cit. 
glas. El orden del capitulado en su libro clásico sigue el mismo orden jerárquico de justificación. Después de una exposición de las diversas teorías generales, que en último término, pueden reducirse a las consecuencialistas y a las deontológicas, el desarrollo principal recae sobre los principios. Finalmente, se dedica un capítulo a las reglas derivadas de las relaciones médico-paciente, y se concluye con otro capítulo dedicado a las teorías particularistas.

Los principios, afirman estos autores, son más generales que las reglas y sirven para justificarlas. Las reglas están especificadas en los contextos y son más restrictivas en su alcance. Beauchamp y Childress parten del enunciado de cuatro principios fundamentales: autonomía o respeto a las personas, a sus opiniones y a elegir y realizar acciones basadas en los valores y creencias personales; no maleficencia, que obliga a no causar daño a otro; beneficencia, que exige prevenir o eliminar el daño y promover el bien; y justicia en el tratamiento igual de las personas a menos que entre ellas se dé una diferencia relevante. Por lo que hace a las reglas, pueden justificarse en un solo principio o en la combinación de varios. Ellas son las reglas de veracidad, privacidad, confidencialidad y fidelidad.

Lo relevante a destacar para nuestros propósitos es que para Beauchamp y Childress los principios deben entenderse prima facie y no como absolutos, es decir, obligan siempre y cuando no entren en conflicto entre sí. Si resulta un conflicto, se deben jerarquizar considerando la situación concreta. No existen criterios para determinar la prioridad de un principio sobre otro, por lo tanto, el recurso final debe ser un consenso entre todos los integrantes, por ejemplo, de un comité decisorio. Dígase lo mismo de las reglas en tanto dependientes de los principios, con la diferencia de que así como los principios no pueden eludir cierta preferencia débil con respecto a alguna de las dos grandes teorías éticas, consecuencialista o deontológica, las reglas no pueden obviar ciertas disposiciones de carácter y virtudes personales en las relaciones médico-paciente, lo que las acerca a las teorías particularistas.

La teoría de Beauchamp y Childress ha representado, sin lugar a dudas, el punto de referencia obligado de los teóricos de la bioética, y también blanco de ataque desde teorías generalistas y particularistas, especialmente de estas últimas, como ya se ha visto. Las sucesivas ediciones de la obra han ido incorporando algunas de esas críticas y las respuestas a las mismas. Quiero detenerme ahora en un artículo ya citado de Tom Beauchamp, que me resulta especialmente interesante porque retoma algunas de las críticas y en su respuesta lo acerca a la idea de un equilibrio reflexivo apartándolo de una concepción estrictamente principalista. 
Como vimos más arriba, Beauchamp rechaza lo que él ha llamado una concepción «robusta» de los principios para adherir a una concepción prima facie. Lo que no es admisible en la concepción robusta, piensa este autor, es el carácter no exceptuable y fundacional de los principios y opone a éstos lo que con Rawls llama «juicios considerados», ponderados o razonables. Un juicio es considerado si cumple con las siguientes condiciones: 1. existe un juicio moral; 2. que se mantiene imparcial; 3 . la persona que realiza el juicio es competente; 4. el juicio es generalizable a todos los casos similares; y 5. es coherente en tanto refleja una rica historia de adaptación a la experiencia moral generando credibilidad y confianza entre los individuos. Estas condiciones no son privativas de los principios, ni de las reglas. Los juicios pueden darse en cualquier nivel de generalidad aun en los juicios sobre los casos concretos. Lo que se requiere es que a partir de su formulación se realice un proceso de ida y regreso, de abajo hacia arriba, y a la inversa, hasta encontrar un punto de equilibrio. Si éste, por ejemplo, se ha alcanzado en un nivel muy particular, es suficiente, sin necesidad de tener que buscar algún principio más general justificatorio. Así por ejemplo, el juicio «los jueces no deben ser influenciados durante sus deliberaciones» en tanto reúne las cinco condiciones señaladas más arriba resulta un buen candidato para un juicio ponderado, sin necesidad de recurrir, o hacerlo descansar, en algún principio ulterior de justificación o en alguna teoría general comprensiva. Con este procedimiento, piensa el autor, se evitan los dos problemas más recurrentes que presenta la concepción robusta: el deductivismo y el distanciamiento de la moralidad común. La concepción prima facie, enfáticamente afirma Beauchamp es enemiga, no amiga del deductivismo. Los principios prima facie no son instrumentos para deducir reglas o juicios no exceptuables. No existe ya una relación de dependencia sino de independencia entre las proposiciones. Más aún, los juicios ponderados tal como se presentan, de acuerdo con el método del equilibrio reflexivo, son compatibles con la casuística y su tesis de los «casos paradigmáticos». $\mathrm{Pa}$ ra que un caso pueda ser comparado y «transportado» a otro caso, hasta dar con el caso paradigmático, es necesario algún nivel de generalidad y de imparcialidad y, en este sentido, la misma idea de «paradigma» contiene ya la de principio prima facie.

En la misma línea del «equilibrio reflexivo», a la que adhiere Beauchamp, se encuentra Dan Brock, quizás uno de los teóricos contemporáneos más importantes en el campo de la bioética. Brock comienza criticando tanto las posiciones generalistas como las particularistas. Las primeras por su deductivismo y las segundas por su rechazo de algún criterio racional e imparcial que permita dirimir los conflictos concretos. No me detendré en estas críticas que, con más o menos especificaciones, han ido apareciendo a 
lo largo del trabajo. Más interesante es su defensa de un equilibrio reflexivo en términos de «consistencia» del propio razonamiento moral. Si bien es inaceptable partir de una teoría general independiente y establecida como la única verdadera, que mecánicamente se aplica para la resolución de los casos concretos, piensa Brock, lo cierto es que cualquier razonamiento en torno a dichos casos supone, implícita o explícitamente, fragmentos o partes de teorías generales. Precisamente, la consistencia en el razonamiento moral significa aceptar las implicaciones de las razones o principios a los que uno apela en la resolución de los casos particulares. Sucede con mucha frecuencia que las convicciones más profundas tienen que ver, no con un juicio o situación determinada, sino con principios generales, y con ciertas teorías implícitas. Así, por ejemplo, el principio de igualdad de oportunidades, característico de una teoría liberal, y de la moral y cultura política americana, en particular, ha sido usado para decidir sobre problemas concretos de inequidad en el acceso a los servicios de salud. Ésta es, sin duda, una concesión que debe hacerse a las teorías generalistas. Pero es cierto, también, que tales convicciones pueden entrar en conflicto con otras convicciones igualmente generales, o bien, con juicios morales sobre casos particulares, y aún con la apreciación sobre los hechos empíricos, con respecto a los cuales tampoco hay consenso. Lo que se requiere entonces es alcanzar un equilibrio reflexivo en el que la revisión de los principios o de las convicciones individuales debe ser tal que permita al individuo conservar el máximo de convicción que sea posible.

Brock se anticipa a una posible crítica. Tomar las convicciones como punto de partida para el equilibrio reflexivo, sean en un dominio particular o más general, que impliquen los valores de una comunidad y de una cultura determinada, ¿no conduciría a un conservadurismo moral, a un reforzamiento del status quo? ¿No estamos finalmente en presencia de un subjetivismo relativista? De ninguna manera, piensa el autor, ya que en el proceso de revisión de las convicciones deben considerarse por igual, y críticamente, las mismas alternativas, por más radicales o aberrantes que ellas fuesen. Si al término de este ejercicio crítico se concluye en la incompatibilidad de dos juicios morales, entonces, sin duda debe asumirse una posición relativista, pero un relativismo que Brock denomina «justificatorio». El debate entre subjetivistas y objetivistas termina resolviéndose, finalmente en favor del primero, si se comprende que al término del proceso deliberativo, las teorías, principios y reglas dependerán de lo que cada individuo esté dispuesto a asumir e incorporar libremente en su vida. La elección de alguno de los dos juicios incompatibles es, sin duda, subjetiva, pero no arbitraria, sino justificada en una deliberación moral pública. 
Antes de pasar al texto de Atienza, vale la pena hacer algunos comentarios a las posturas de Beauchamp y Brock. Con respecto al primero, pienso que el recurso al «equilibrio reflexivo» lleva toda la intención de tomar distancia de esquemas generalistas-deductivistas e incorporar los principios generales al discurso moral con un valor prima facie. Esto me parece aceptable. Lo que no queda claro es cómo hacer compatible entre sí algunas de las condiciones que señala el autor para que exista un juicio ponderado. ¿Cómo es posible sostener al mismo tiempo la condición de imparcialidad con la de coherencia? Si la imparcialidad supone un punto de vista moral crítico que, por definición, requiere asumir una posición independiente de las situaciones particulares, y la coherencia, sólo es comprensible en términos de una adaptación de los principios a la moral positiva de una comunidad cultural determinada - por más «rica» que ésta sea- entre ambas condiciones puede darse una incompatibilidad manifiesta. Ser imparcial podría significar, eventualmente, estar en contra de la moral positiva de una comunidad, es decir, ser a la vez, incoherente. Vale también la inversa. Pero lo que resulta más difícil comprender es que se exijan como condiciones del juicio ponderado la imparcialidad y la generalidad, y aún la propia coherencia, y a la vez, se sostenga que tales juicios no son dependientes sino independientes. Cualquier generalización requiere de algún metacriterio para la comparación de los casos a no ser que generalizar se reduzca a una simple enumeración y conteo de los mismos. Y esto no es lo que se propone. Con más razón en relación a la imparcialidad, con respecto a la cual el metacriterio se constituye en una razón justificatoria y, por lo tanto, exige establecer un vínculo de dependencia con el juicio particular. La misma condición de coherencia demanda una relación de dependencia ente el juicio particular y un convencionalismo social, como criterio. Creo que, finalmente, el autor termina concediendo demasiado a la casuística, quizás en un empeño por tomar distancia de las críticas a su teoría principalista inicial.

Brock parte de una concepción del «equilibrio reflexivo», no en términos de coherencia sino de consistencia. Reconoce la relación de dependencia de los juicios particulares con los principios como razones justificatorias y, finalmente, la comprensión de una teoría general implícita en la elección de los mismos. La defensa de un equilibrio reflexivo no tiene por qué estar reñida con principios justificatorios y, por lo tanto, con relaciones de dependencia. Esto creo que es correcto. Lo cuestionable de su propuesta es, por una parte, el criterio de corrección del «equilibrio reflexivo», es decir, el criterio que afirma que se debe procurar conservar el máximo de convicción posible y, por la otra, lo que denomina, con poco acierto a mi juicio, relativismo justificatorio. ¿Qué significa en el proceso de revisión entre principios y juicios particulares llegar al punto en el que el criterio sea que 
el individuo, o los individuos, conserven el máximo de convicción? Resulta claro que si no hay conflicto, es decir, nadie tiene convicciones sobre juicios particulares o principios generales que choquen entre sí, no es necesario buscar un equilibrio. Puede ser que en el mismo proceso de deliberación desaparezca la convicción y entonces el conflicto quede resuelto. Pero si éste persiste, no basta con proponer que se mantenga el máximo de convicción que sea posible, sino que se requiere de algún criterio para determinar, precisamente, qué es lo máximo y qué es lo posible. Brock está consciente que el criterio de corrección es insuficiente. Puesto que rechaza la posibilidad de un objetivismo ético, aun en los términos de un consenso sobre hechos empíricos, la vía que encuentra más aceptable es la del subjetivismo. No un subjetivismo arbitrario y conservador - puesto que tal subjetivismo es el resultado de un proceso de discusión pública en el que se han ponderado aún las posiciones más radicales- sino justificatorio y, finalmente, individual. Y esto es lo que resulta confuso. Que al final de un proceso arduo de deliberación, en el que se concluye con juicios antagónicos, sea el individuo el que debe decidir qué opción seguir y cómo incorporarla en su vida, es algo obvio que un liberal no puede más que aplaudir, pero no es éste el problema que está a discusión. Estas decisiones en términos de autenticidad, sinceridad, hipocrecía, tan caras a filósofos como Charles Taylor y Bernard Williams, puede ser interesante analizarlas desde un punto de vista psicológico y social, pero no desde el punto de vista de una moral crítica. Aquí lo que se requiere son criterios morales que permitan decidir con alguna pretensión de corrección, imparcialidad y objetividad, con el fin de consensuar reglas que orienten y ordenen las conductas de los individuos. En este sentido, un subjetivismo justificatorio, desde mi punto de vista, resulta ser una contradictio in terminis.

En un texto, multicitado en el contexto de la discusión sobre bioética en habla castellana, Manuel Atienza ofrece una de las contribuciones más lúcidas en el debate que nos ocupa. «Juridificar la bioética» no es, de acuerdo con el autor, el título de un artículo que pretenda «una vuelta a la deontología médica tradicional, esto es, a la concepción de la ética médica -y, por extensión, de la bioética- como un código único de preceptos y obligaciones aplicados según procedimientos burocráticos y respaldados coactivamente»; de lo que se trata, más bien, es de «sostener que hay un tipo de conflicto jurídico cuya resolución consiste justamente en "ponderar" principios contrapuestos y que, para tratar con esos casos, se ha ido desarrollando una metodología que podría resultar de utilidad también para la aplicación de los casos concretos de los principios de la bioética». Después de pasar revista y criticar la teoría «principalista» de Beauchamp y Childress; la tópica o «casuística» de Jonsen y Toulmin; y la que, a reserva de un me- 
jor nombre, podría denominarse la de «principios jerarquizados» del filósofo español Diego Gracia; Atienza desarrolla su propia concepción. Quiero comentar su propuesta a partir de tres premisas básicas: la aceptación de un objetivismo moral; una ordenación jerarquizada de principios primarios y secundarios; y la distinción entre principios y reglas.

Para Atienza la tópica de Jonsen y Toulmin y el modelo propuesto por Diego Gracia, sobre el que regresaré en seguida, «apuntan en la dirección adecuada al esforzarse por construir una ética -o una bioética- que proporcione criterios de carácter objetivo y que, por así decirlo, se sitúe a mitad del camino entre el absolutismo y el relativismo moral», aunque el autor los critique inmediatamente, por otras razones. Si bien Atienza no desarrolla en este trabajo su concepción metaética objetivista, creo que es uno de los supuestos básicos para dar sentido al mismo. Por lo pronto, como bien lo ha mostrado James Fishkin, no debe confundirse el objetivismo con el absolutismo moral, ni mucho menos con el relativismo. ${ }^{25}$ En la línea de Mario Bunge y Ernesto Garzón Valdés pienso que Atienza no tendría mayor inconveniente en aceptar que se puede alcanzar un consenso profundo con respecto a las necesidades básicas que demanda cualquier ser humano -para nuestro caso en materia de salud y medicina- y que tales necesidades no son objeto de negociación, ni de acuerdos mayoritarios, ni sujetas a los valores culturales de una comunidad. Creo que también estaría de acuerdo en que la exigencia de satisfacción de tales necesidades es una condición necesaria para el ejercicio de la autonomía personal ${ }^{26}$; que «los hombres tienen derecho a no ser dañados en sus intereses vitales y tienen el deber de no dañar a los demás impidiendo la satisfacción de sus necesidades básicas o de sus intereses vitales» ${ }^{27}$, y que la consideración igualitaria de las personas en sus exigencias de cuidado y salud supone el rechazo de cualquier trato discriminatorio por razones de sexo, raza, convicciones religiosas, etc. En síntesis, que los principios normativos de autonomía, beneficencia, no maleficencia e igualdad, no se construyen arbitrariamente, ni se proponen dogmáticamente, sino

${ }_{25}$ James Fishkin, Justice, Equal Opportunity and the Family, Yale University Press, New Haven, 1983, pp. 169 ss. Y, del mismo autor, «Las fronteras de la obligación», en Doxa, No. 3, Alicante, 1986, pp. 80-82. Como señala Fishkin, existe una tendencia común a creer que cualquier alejamiento del absolutismo moral, por mínimo que éste sea, conduce irremediablemente al relativismo o a la arbitrariedad. Uno de los ejemplos más ilustres de esta posición es el de Leo Strauss, que en su crítica a Isaiah Berlin reprocha a éste su intento de ubicarse en un punto intermedio entre el relativismo y el absolutismo con la propuesta de un objetivismo pluralista de los valores. Véase pp. 190 y ss.

${ }^{26}$ Véase Carlos Nino, «Autonomía y necesidades básicas», Doxa, No. 7, Alicante, p. 22.

${ }^{27}$ Ernesto Garzón Valdés, «Necesidades básicas, deseos legítimos y legitimidad política en la concepción ética de Mario Bunge», en Derecho, ética y política, Centro de Estudios Constitucionales, Madrid, 1993, pp. 546 y ss. 
que se levantan sobre la aceptación de un dato cierto: el reconocimiento y la exigencia de satisfacción de las necesidades básicas. Es la afirmación de este objetivismo moral el que permite tomar distancia por igual de las teorías generalistas y particularistas en bioética y, por lo tanto, del absolutismo y el subjetivismo moral, que las caracterizan, respectivamente.

La crítica de Atienza a la concepción de Diego Gracia va delineando lo que luego será su propuesta de orden y enunciado de los principios. Para Gracia, en la interpretación de Atienza, los cuatro principios clásicos de la bioética no tienen el mismo rango porque su fundamentación es distinta: «La no-maleficencia y la justicia se diferencian de la autonomía y la beneficencia en que obligan con independencia de la opinión y la voluntad de las personas implicadas, y [...] por tanto, tienen un rango superior a los otros dos». Los principios del primer nivel -no maleficencia y justicia- son, además, «expresión del principio general de que todos los hombres somos básicamente iguales y merecemos igual consideración y respeto». ${ }^{28}$ Atienza critica a Gracia, creo que con razón, en el sentido de que la división de los principios que sugiere no está justificada: «Por un lado, el fundamento de esa jerarquización (el hecho de que unos obligan con independencia de la opinión y la voluntad de los implicados) parece envolver una suerte de petición de principio: si se acepta el criterio, entonces, obviamente, la autonomía ha de tener un rango subordinado, pero lo que no se ve es por qué ha de ser ése el criterio de la jerarquía; esto es, queda sin fundamento por qué la opinión y la voluntad de los implicados -o sea, la autonomía- ha de subordinarse a alguna otra cosa, a algún otro valor». Por otro lado, si se acepta la prioridad del principio de igual consideración y respeto por encima del de autonomía, «no se entiende muy bien por qué la opinión y la voluntad de un individuo ha de contar menos que la de otro, esto es, no se entiende por qué la autonomía no es también expresión de ese principio general». ${ }^{29}$

Atienza propone cuatro principios ordenados de la siguiente manera: autonomía, dignidad, igualdad e información. Estos principios responden a las siguientes preguntas: «a) ¿quién debe decidir (el enfermo, el médico, los familiares, el investigador)?; b) ¿qué daño y qué beneficio se puede (o se debe) causar?; c) ¿cómo debe tratarse a un individuo en relación con los demás?, y d) ¿qué se debe decir y a quién?» Estos cuatro principios serían suficientes para resolver los «casos fáciles», pero son insuficientes para los «casos difíciles». Para éstos se requeriría de principios secundarios que derivaran de los primarios de modo tal que ante la insuficiencia del principio de autonomía se apelara al principio de paternalismo justificado; de la insuficiencia del de dignidad al de utilitarismo restringido; del de igualdad al

\footnotetext{
${ }^{28}$ Citado po Manuel Atienza, op. cit., pp. 67 y ss.

${ }^{29}$ Ibid.
} 
de trato diferenciado y del de información al de secreto. En el discurso práctico -por ejemplo, en un comité de ética- se podría establecer «una cierta prioridad en favor de los primeros, que podría adoptar la forma de una regla de carga de la argumentación: quien pretenda utilizar, para la resolución de un caso, uno de estos últimos principios (por ejemplo, el de paternalismo frente al de autonomía, etcétera) asume la carga de la prueba, en el sentido de que es él quien tiene que probar que, efectivamente, se dan las circunstancias de aplicación de ese principio». ${ }^{30} \mathrm{El}$ enunciado de los principios secundarios que Atienza propone sería como sigue:

Principio de paternalismo justificado: «Es lícito tomar una decisión que afecta a la vida o salud de otro si: a) este último está en situación de incompetencia básica; b) la medida supone un beneficio objetivo para él, y c) se puede presumir racionalmente que consentiría si cesara la situación de incompetencia.»

Principio de utilitarismo restringido: «Es lícito emprender una acción que no supone un beneficio para una persona (o incluso que no le supone un daño), si con ella: a) se produce (o es racional pensar que podría producirse) un beneficio apreciable para otro u otros; b) se cuenta con el consentimiento del afectado (o se puede presumir racionalmente que consentiría), y c) se trata de una medida no degradante.»

Principio de trato diferenciado: «Es lícito tratar a una persona de manera distinta que otra si: a) la diferencia de trato se basa en una circunstancia que sea universalizable; b) produce un beneficio apreciable en otra u otras, y c) se puede presumir racionalmente que el perjudicado consentiría si pudiera decidir en circunstancias de imparcialidad.» ${ }^{31}$

Atienza enuncia un cuarto principio secundario -el del secreto- que correspondería al principio primario de información. ${ }^{32}$ Creo que este par de principios podría subsumirse adecuadamente en el principio de autonomía personal y de paternalismo justificado, respectivamente. Parece claro que para que un individuo pueda decidir con respecto a aquello que le afecte a su salud es una condición necesaria que se encuentre debidamente informado. La doctrina del «consenso informado», tan desarrollada en el contexto anglosajón, es una prolongación natural del debido respeto a la autonomía de cada individuo.

Con todo, sea mediante principios primarios y secundarios, por su carácter de «inconcluyentes», no sería posible aún resolver definitivamente un ca-

\footnotetext{
${ }^{30}$ Ibid., pp. 83 y ss.

31 Ibid.

${ }^{32}$ Para un análisis del secreto médico en relación con el paternalismo, véase Ramón Casals Miret y Lydya Buisán Espeleta, «El secreto médico», en María Casado, Bioética, derecho y sociedad, Madrid, Trotta, 1998, pp. 151-176.
} 
so. Por tanto, además de principios son necesarias las reglas, es decir, «un conjunto de pautas específicas que resulten coherentes con ellos y que permitan resolver los problemas prácticos que se plantean y para los que no existe, en principio, consenso». El problema fundamental de la bioética no sería otro, en definitiva, que el de pasar del nivel de los principios al de las reglas. Atienza ilustra este tránsito de niveles con varios ejemplos: a) ante el caso controvertido de la transfusión sanguínea a un niño Testigo de Jehová, el principio primario de autonomía personal de los padres, debe ceder ante el principio secundario de paternalismo justificado que justifica la regla: «un padre no puede impedir que a su hijo se le trasfunda en caso de necesidad»; b) ante la situación concreta de acceder a los órganos de un cadáver, el posible principio primario de dignidad del cadáver y el de autonomía de los parientes, debe ceder ante el principio secundario del utilitarismo restringido que justifica la regla: «es lícito trasplantar un órgano de un fallecido sin contar con el consentimiento de sus familiares»; c) ante la escasez de órganos y la creciente demanda de los mismos, el principio primario de igualdad debe ceder ante el principio secundario de trato diferenciado que justifica la regla: «Es lícito preferir para un trasplante (a igualdad de otras condiciones) al enfermo que pueda pronosticarse una mayor cantidad y calidad de vida».

Regresando a las preguntas iniciales pienso que es precisamente en este proceso deliberativo de ponderación de principios y de tránsito de los principios a las reglas donde la actividad del filósofo desempeña un papel importante. Con todo, que los principios normativos sean relevantes para orientar las decisiones de los funcionarios públicos de la salud o de los miembros de los comités de bioética parece claro siempre que se aceptan algunas condiciones: 1. su pluralidad e inconmensurabilidad; 2 . su objetividad en tanto expresan la exigencia de satisfacción de necesidades básicas; 3 . su valor prima facie; 3. la distinción entre principios primarios y secundarios; y 4. el tránsito necesario de los principios a las reglas para la resolución de las situaciones concretas y conflictivas. El conjunto de principios y reglas -de resoluciones que fueran emanando de cada uno de los comités hospitalarios, estatales y a nivel nacional- irían conformando, como lo sugiere el propio Atienza, una suerte de «jurisprudencia», que garantizaría continuidad en las decisiones y seguridad entre los ciudadanos. Que la elección y conformación de tales principios y reglas suponga alguna teoría general implícita creo, con Dan Brock, que resulta inevitable, pero de ninguna manera debe ser un impedimento para resoluciones argumentadas y eficaces.

\section{DOXA 23 (2000)}

